\title{
PROMOÇÃO DE HABILIDADES GRÁFICAS NO CONTEXTO DA HOSPITALIZAÇÃO ${ }^{1}$
}

\author{
IMPROVING GRAPHIC SKILLS DURING HOSPITALIZATION
}

\section{LAS HABILIDADES GRÁFICAS MEJORANDO DURANTE LA HOSPITALIZACIÓN}

\section{Ana Cláudia Afonso Valladares ${ }^{2}$, Ana Maria Pimenta Carvalho ${ }^{3}$}

RESUMO: A hospitalização pode ter efeitos negativos sobre o desenvolvimento infantil. Este processo impede que a criança continue em sua rotina diária e freqüente ambientes estimuladores. O objetivo deste trabalho foi avaliar o desenvolvimento e a qualidade da produção gráfica, antes e após intervenção em arteterapia, de crianças com idade de 7 a 10 anos internadas devido a moléstias infecciosas. Foi utilizado um esquema quasi experimental com grupo controle $(n=09)$ e um grupo experimental $(n=10)$ submetido a intervenções, tendo sido coletado material para avaliação antes e após a intervenção. Os resultados mostram que estas foram eficazes em promover a qualidade das produções. Conclui-se que os hospitais podem ser ambientes estimulantes para a criança, implementando suas práticas de cuidados para além da doença.

PALAVRAS CHAVES: Terapia pela arte; Enfermagem Pediátrica; Hospitalização.

ABSTRACT: Hospitalization may have negative effects on child development. It takes the child off her routine and prevents her from contacts with stimulating environments. The aim of this work was to evaluate the development and quality on drew productions, before and after art therapy intervention, during the hospitalization of 7 to 10 years old children, with infectious diseases. It was proposed a quasi experimental design with a control group $(n=9)$ and a group that was submitted to art therapy intervention $(n=10)$. Results show that these interventions were effective in improving the development and the quality of the drawings. Hospitals can also be stimulating environments for children offering them caring practices that go beyond the disease.

KEY WORDS: Art therapy; Pediatric Nursing; Hospitalization.

RESUMEN: La hospitalización puede traer efectos negativos en el desarrollo del niño. Este proceso impidió la rutina normal de los niños. El objetivo de este trabajo fue evaluar el desarrollo y calidad de dibujos, antes y después de la intervención de terapia con arte de los niños con edad entre 7 y 10 años viejos, internados a causa de enfermedades infecciosas. Fue usado un plan casi experimental con un grupo de control $(n=9)$ y un grupo que se sometió a la intervención de terapia con arte $(n=10)$. Los resultados mostraron que estas intervenciones fueran eficaces mejorando el desarrollo y la calidad de las producciones gráficas. Los hospitales también pueden ser ambientes estimulantes para los niños y les ofrecieren prácticas cuidadosas que van más allá de la enfermedad.

PALABRAS-CLAVE: Terapia con Arte; Enfermería Pediátrica; Hospitalización.

\footnotetext{
${ }^{1}$ Trabalho extraído da dissertação de Mestrado da primeira autora.

${ }^{2}$ Arteterapeuta e Enfermeira, Profa Assistente da Faculdade de Enfermagem da Universidade Federal de Goiás (FEN/UFG) e Doutoranda do Programa de Pós-graduação em Enfermagem Psiquiátrica pela Escola de Enfermagem de Ribeirão Preto da Universidade de São Paulo (EERP/USP). FEN/UFG - Goiânia/GO E-mail: aclaudiaval@terra.com.br

${ }^{3}$ Psicóloga, Docente do Departamento de Enfermagem Psiquiátrica e Ciências Humanas da EERP/USP. Ribeirão Preto, São Paulo. (Orientadora do estudo).
} 


\section{INTRODUÇÃO}

A arteterapia não é mero entretenimento, mas sim uma forma de linguagem que permite à pessoa comunicar-se com os outros. Desse modo, possibilita à criança não só a liberdade de expressão, mas também sustenta a autonomia criativa, ampliando seu conhecimento sobre o mundo e proporcionando seu desenvolvimento tanto emocional, como social. Por conseguinte, pode ser de grande valor para aquelas que apresentam patologias diversas e estão hospitalizadas (VALLADARES, 2003; 2004b; VALLADARES \& CARVALHO, 2005).

Cada modalidade expressiva tem propriedades terapêuticas inerentes e específicas, e cabe ao arteterapeuta construir um repertório de informações relativas a cada uma, com o intuito de adequar as modalidades expressivas e materiais às analogias e quadros clínicos atendidos (PHILIPPINI, 2005; VALLADARES \& NOVATO, 2001).

O desenho como modalidade da arteterapia, objetiva a forma, a precisão, o desenvolvimento da atenção, da concentração, da coordenação viso-motora e espacial. Também concretiza alguns pensamentos e exercita a memória. $\mathrm{O}$ desenho está relacionado ao movimento e ao reconhecimento do objeto, tendo a função ordenadora (VALLADARES, 2004a; 2004b).

FRANCISQUETTI (2005a; 2005b) explica que a leitura dos desenhos sinaliza as palavras que não podem ou não conseguem ser ditas pelas crianças. Sendo que as aferências de comunicação não-verbais se transformam em processo cognitivo, e são importantes de serem comparadas em diferentes momentos para perceber as mudanças externas, como também internas as crianças.

No caso das crianças, o adoecimento favorece alterações na sua vida, como um todo, podendo, muitas vezes, desequilibrar seu organismo interna e externamente, o qual, em conseqüência disso, gerará um bloqueio no processo de desenvolvimento saudável das crianças, especialmente se a doença for longa e duradoura (WHALEY \& WONG, 1999; ANGERAMICAMON, 2002; DIAS et al, 2003).

O desenvolvimento infantil é um processo complexo, que envolve as diferenças individuais e as específicas de cada período, como mudanças nas características, nos comportamentos, nas possibilidades e nas limitações de cada fase da vida, indistintamente. A singularidade das crianças lhes é conferida por influências de seu ritmo próprio de desenvolvimento e por características pessoais que as diferenciam das demais (WHALEY \& WONG, 1999).

Conforme SIGAUD \& VERÍSSIMO (1996), o período que vai de sete aos dez anos de idade, objeto de estudo deste trabalho, e que se convencionou chamar de escolar, é decisivo para a estruturação harmoniosa do indivíduo. Nesta etapa, ocorrem transformações significativas nos vários aspectos cognitivos, socioemocionais e da comunicação gráfica. O raciocínio da criança esta fase esta mais lógico, compreende melhor os fatos (WHALEY \& WONG, 1999); ademais, a criança, neste período, amplia suas relações, distanciando-se do convívio familiar, movendo-se em direção ao contexto social e aos grupos de pares e passa a ser menos egocêntrica (SIGAUD \& VERÍSSIMO, 1996).

Em relação ao desenvolvimento evolutivo da arte infantil, segue seu percurso paralelo ao desenvolvimento geral da criança. Vários autores abordam as teorias do desenvolvimento gráfico infantil, no entanto, teóricos como Luquet (MEREDIEU, 2000) e Lowenfeld (LOWENFELD \& BRITTAIN, 1977) tiveram papel fundamental na construção do alicerce de entendimento da produção gráfica das crianças, sendo largamente utilizadas na atualidade. Para a fase do escolar, Luquet descreve o realismo intelectual, dos 4 a 10 anos e o realismo visual, dos 7 aos 9 anos. Lowenfeld propôs em seus trabalhos os estágios de esquemático, dos 7 aos 9 anos e realismo, dos 9 aos 11 anos (LOWENFELD \& BRITTAIN, $1977 \mathrm{e}$ MEREDIEU, 2000).

Na concepção de Luquet, o estágio do realismo intelectual contém algumas características que se assemelham ao pensamento de Lowenfeld para a fase esquemática e apresentam algumas características de destaque que serão expostas a seguir:

- A criança não representa o real, mas sobretudo o que sabe sobre o objeto;

- Aparecem os planos deitados (axial e irradiante), mas não há o compromisso formal com a perspectiva. A criança usa a descontinuidade, o rebatimento, a transparência, a planificação e a mudança de pontos de vista;

- A representação espacial amplia-se, surgindo a linha de base (real ou implícita) que simboliza a superfície em que as coisas são colocadas; em outras vezes, serve para representar o horizonte da paisagem;

- A partir dos sete anos a criança mostra mais claramente em seus desenhos as influências das mediações sociais, históricas e culturais. Seu cotidiano aparece mais claramente nesse universo representativo de pessoas, animais, brinquedos, objetos, natureza, produções culturais e sociais de sua época, como televisão, histórias em quadrinhos, desenho, jogos, brincadeiras.

$\mathrm{Na}$ teoria de Luquet, o estágio do realismo visual apresenta algumas características de destaque e 
semelhantes à teoria de Lowenfeld, na fase naturalista, expostas a seguir:

- Dos desenhos surgem a perspectiva e se submetem às suas leis, criando, assim, planos e sobreposições. Nesse estágio, a criança começa a unir as duas linhas, usa cores mais vivas no primeiro plano e mais baixas nos outros, criando a ilusão de profundidade e primeiro plano. A linha de base e o céu permanecem, mas ainda não estão presentes a luz, a sombra e a tridimensionalidade, é apenas seu início;

- A criança simboliza o objeto de acordo com sua aparência visual. Nessa fase, há a tendência da reprodução da realidade para os objetos, personagens, elementos da natureza, locais etc. A cor também é realista; ela substitui a transparência pela opacidade e suprime os detalhes invisíveis do objeto;

- Aumenta a busca por detalhes, preocupa-se com o acabamento e aparecimento de novas formas. Conseqüentemente, aparecem as linhas de contorno e o esquema corporal torna-se mais completo.

Em fases anteriores ao do escolar, para os autores citados anteriormente, aparecem as fases de garatuja, significando a representação de movimentos aleatórios ou círculos isolados; e a fase préesquemática caracterizada pela formação da imagem corporal e a mandala sem linha de chão.

Verificam-se novas e diferentes formas de desenvolvimento e, nesse sentido, LOWENFELD \& BRITTAIN (1977) dizem-se convencidos de que a arte deve, certamente, apoiar a expressão individual e o pensamento criador da criança. Caso seja bloqueado a desenvolvimento normal da criança, este se refletirá também no seu desenvolvimento gráfico, pressume-se que os conteúdos das produções simbólicas ao serem analisados registravam os momentos afetivos das crianças. A criança ao produzir imagens está produzindo a si mesma seu mundo físico (sensório motor), mental (cognitivo), emocional, imaginação, o mundo das idéias, dos sonhos, e da memória.

O objetivo deste trabalho foi avaliar 0 desenvolvimento e a qualidade da produção gráfica, antes e após intervenção em arteterapia, de crianças com idade de 7 a 10 anos internadas devido a moléstias infecciosas.

\section{MÉTODO}

a) Tipologia: trabalhou-se com a abordagem quantitativa, com delineamento quasi-experimental.

b) Amostra e local: foi caracterizada por dezenove crianças internadas no hospital HDT de Goiânia - Goiás, no período de janeiro a maio de 2003, sendo dez do grupo experimental (grupo que passou por intervenções em arteterapia) e nove do grupo controle (grupo que não passou por intervenções em arteterapia), pois um recusou a desenvolver esta modalidade. Os grupos foram constituídos por ambos os sexos, na faixa etária entre sete anos e sete meses a dez anos e onze meses de idade.

c) Procedimentos: este estudo é parte da dissertação das autoras e intitulada: "Arteterapia com crianças hospitalizadas" que foi aprovado pelo Comitê de Ética em Pesquisa Médica Humana e Animal do HAA/HDT/SES. As crianças e seus responsáveis foram consultados quanto a sua participação, no qual foram (os responsáveis) solicitados a assinar o Termo de Consentimento Livre e Esclarecido, conforme as normas de pesquisa com seres humanos - Resolução n¹96/96 (BRASIL, 1996).

Os desenhos das crianças foram analisados quanto ao nível de desenvolvimento gráfico infantil e de sua qualidade, conforme os estágios e Luquet e Lowenfeld, e foram avaliados antes (avaliação inicial) e após as intervenções de arteterapia (avaliação final). Essa técnica teve uma temática padronizada, de modo que foram propostas para as avaliações (inicial e final) um desenho com a representação do próprio hospital em uma contextualização livre. Estimulou-se ainda a criança a dar um título para a obra produzida e falar sobre o mesmo, caso quisesse.

Os instrumentos empregados para análise dos dados foram: ficha de avaliação do desenvolvimento gráfico bidimensional da criança, adaptação ao modelo de COSTA (1997) - no qual se avaliou o desenvolvimento do desenho, conforme as fases de Luquet e Lowenfeld (realismo intelectual/fase esquemática, realismo visual/fase naturalista ou ainda fases anteriores ou posteriores ao escolar); e o roteiro para avaliação da produção gráfica infantil, adaptação do modelo de VALLADARES (2003) - no qual se avaliou a qualidade do desenho e seguiu-se um modelo com parâmetros pré-estabelecidos. Os itens avaliados na qualidade do desenho foram: variedade de elementos, cor, configuração das imagens, criatividade, simetria, regularidade, complexidade, unidade, equilíbrio, atividade, exatidão e profundidade.

Após a elaboração destes instrumentos, estes foram submetidos ao julgamento de juízes que emitiram pareceres quanto aos mesmos. Após as correções convenientes, realizou-se o teste piloto com vistas à verificação da operacionalidade dos mesmos. Estes instrumentos foram utilizados com a observação de um auxiliar de pesquisa, um profissional da área ou de áreas afins, que passou por um treinamento prévio e compartilhou das avaliações com a arteterapeuta, caracterizando uma reflexão compartilhada entre ambos. 
As intervenções em arteterapia consistiram de acompanhamento individual em sete sessões, durante três dias e meio consecutivos, com duração variada de uma hora a três horas e meia. Durante as intervenções foram trabalhadas várias modalidades de arte $\mathrm{e}$ apoiadas às necessidades da criança. Essas intervenções em arteterapia favoreceram a conduta focal e imediata, reforçando, assim, o vínculo. As intervenções consistiram de técnicas lúdicas e de atividades artísticas e a condução das dinâmicas foi espontânea, favorecendo a exteriorização da subjetividade da criança. Durante as intervenções foram utilizados, no total, materiais de desenho, pintura, colagem e recorte, modelagem, construção, gravura, origami, teatro, brinquedos, jogos, livros de histórias e escrita criativa. d) Análise dos dados: para análise comparativa foi aplicado o teste T de Wilcoxon (SIEGEL, 1975) para as duas amostras dependentes. Nesses protocolos de avaliação realizados, estão contidas escalas de classificação nas ordens de qualidade do desempenho. Quanto ao desempenho, foram atribuídos níveis de gradação de pontos na ordem crescente, isto é, do nível inferior para o superior de qualidade.

\section{RESULTADOS E DISCUSSÃO}

O Quadro 1 exibe os resultados obtidos nas avaliações inicial e final comparando-se os dois grupos A (experimental) e B (controle), quanto à modalidade gráfica.

Quadro 1: Comparação* intragrupo dos escores obtidos na avaliação inicial e avaliação final com relação ao desenvolvimento e produção plástica, Goiânia/GO - 2003

\begin{tabular}{|l|l|l|}
\hline Modalidades & GA & GB \\
\hline Desenvolvimento gráfico & $\mathrm{Al}<\mathrm{AF}^{1}$ & $\mathrm{Al}=\mathrm{AF}$ \\
\hline Qualidade do Desenho & $\mathrm{Al}<\mathrm{AF}^{1}$ & $\mathrm{Al}>\mathrm{AF}^{2}$ \\
\hline
\end{tabular}

*Teste T de Wilcoxon (SIEGEL, 1975)

$1 p<0,01 \quad 2 p<0,05$

GA (Grupo A - experimental): $n=10$ GB (Grupo B - controle): $n=09$

Al: avaliação inicial (antes das intervenções de arteterapia)

AF: avaliação final (após as intervenções de arteterapia)

No que se refere ao desenvolvimento gráfico, o grupo A (experimental) apresentou progresso, tendo demonstrado na avaliação final diferenças estatisticamente superiores à avaliação inicial, sobretudo porque, na avaliação inicial, o desenvolvimento gráfico de algumas crianças atingiu níveis inferiores à idade (etapas como de garatuja e do pré-esquemático); atingindo posteriormente níveis mais adequados à idade na avaliação final (realismo intelectual/fase esquemática, realismo visual/fase naturalista de Luquet e Lowenfeld). Quanto ao grupo B (controle), este não mostrou modificação significativa nos dois momentos de avaliações (inicial e final), especialmente por ter havido estabilidade nos níveis de desenvolvimento gráfico.

Observa-se que o nível de desenvolvimento aquém do esperado para idade possivelmente foi corrigido com as intervenções de arteterapia. Conforme apontado por FRANCISQUETTI (2005a; 2005c), a arte ajuda a reduzir a confusão cognitiva da criança, concentrando sua atenção no uso de materiais empolgantes, repletos de magia como: cores, formas, brilhos, texturas, papéis, lápis, tintas etc.

Cabe salientar que esses dados são confirmados por ZIMMERMANN (1997) e PAIN \& JARREAU (2001), quando expõem que a arteterapia é promotora de experiências reestruturantes e muito eficaz no tratamento para os que sofrem de déficits de aprendizagem ao longo do período de desenvolvimento infantil.

O Quadro 1 ainda mostra que na qualidade do desenho, as crianças do grupo A (experimental) apresentaram progresso, tendo as comparações entre os escores obtidos nas avaliações inicial e final apresentado diferença estatisticamente significante. O que mais variou foram, sobretudo, os aspectos relacionados à variedade da produção plástica, policromia, criatividade, complexidade e atividade dos trabalhos. O grupo B (controle), na avaliação final, demonstrou retrocesso estatisticamente significativo em relação à avaliação inicial, pelo empobrecimento da produção gráfica, monocromia, simplicidade, menor atividade e planura das produções gráficas.

A maior variedade na produção expressiva ocorreu com o grupo A (experimental). Segundo ALLESSANDRINI (2004), a arteterapia possibilita que as crianças descubram suas potencialidades e ampliem seu repertório e seu universo pessoal, recontextualizando antigos bloqueios que se desmancham e que adquirem novos significados.

Segundo PAIN \& JARREAU (2001), as cores são fundamentais no processo de arteterapia, pois elas possuem um código subjetivo com ressonâncias e associações às experiências vividas. Assim, a 
constância das manifestações entre cores e os afetos, entre as sensações de cores e as sensações produzidas por outros sentidos, como também entre o investimento dos objetos e a marca colorida permitem decifrar o que os sujeitos exprimem, tendo a cor como um signo rico de significados embutidos.

GOLINELLI (2002) expõe que a arteterapia contribui para estimular a criatividade, porque se vale, em sua aplicação e método, de variadas formas e expressão, fazendo florescer as potencialidades criativas e latentes dos indivíduos.

A complexidade (riqueza de detalhes) está vinculada à variedade expressiva e à criatividade, pois à medida que as crianças do grupo $\mathrm{A}$ (experimental) ampliaram seu mundo imaginativo, favorecido pela intervenção arteterapêutica, introduziram-se modificações em seu mundo interno e em suas imagens. Assim, a criança vai descobrindo e construindo as novas potencialidades adquiridas.

Conforme as afirmações de PAIN \& JARREAU (2001), o sujeito tem tendência a projetar seu próprio corpo sobre a imagem que ele mesmo produz. Assim, semelhantes às motivações emocionais que provocam rigidez no indivíduo, as imagens se traduzem em ausência de movimento. Os autores continuam esclarecendo que o procedimento arteterapêutico consiste em despertar o desejo vital do gesto, em fazêlo sentir fortemente no próprio corpo e em encorajá-lo a buscar os meios plásticos para traduzir essas vivências sensório-motoras em imagens.

\section{CONSIDERAÇÕES FINAIS}

A criança, durante o seu desenvolvimento normal, explora e interage com seu meio de forma contínua quando the são oferecidas oportunidades em ambientes considerados como favoráveis. Cuidar de quem se encontra fragilizado e internamente desorganizado em função de sua doença grave não é tarefa fácil e cabe ao arteterapeuta, que é um facilitar do processo da criança, propiciar um espaço não ameaçador, que propicie o restabelecer do diálogo (comunicação) dessa criança com o mundo.

Portanto, prestar uma assistência globalizada à criança é providenciar um meio ambiente facilitador e propício ao comportamento e desenvolvimento da criança é possível através das intervenções de arteterapia, sendo que a estagnação de estímulos pode prejudicar estruturalmente todo o processo de desenvolvimento normal.

Pode-se deduzir que o desenho é manifestação de uma necessidade importante para as crianças conhecerem, agirem sobre o mundo e comunicarem com ele. Ademais, o desenho é uma atividade que envolve um exercício mental, emocional e intelectual.
Ao desenhar, a criança demonstra sentimentos como alegria ou tristeza; extravasa tensões, angústias, medos, agressividade, assim, ela relaxa e isso a faz bem e a dá prazer.

$\mathrm{Na}$ arteterapia os conteúdos do inconsciente podem ser registrados através da produção simbólica (imagens), através da cor, formas, movimentos, ocupação no suporte e padrões expressivos gerais que acompanham um processo de transformação e que ganham consistência a partir da criação gráfica.

Após a realização deste trabalho, acredita-se que o desenvolvimento de espaços de desenho possa facilitar a expressão de uma forma mais produtiva, colaborando com o desenvolvimento das potencialidades expressivas nas crianças, agindo preventivamente e evitando-se a possibilidades de instalação de algumas disfunções no desenvolvimento normal infantil.

Ao mesmo tempo em que as crianças não conseguem facilmente comunicar verbalmente seus desejos e necessidades, sendo que o desenho representaria a defesa do direito de qualquer criança hospitalizada. Ademais, este estudo contribui para o avanço do conhecimento na área da comunicação gráfica de crianças hospitalizadas.

\section{REFERÊNCIAS BIBLIOGRÁFICAS}

\section{ALLESSANDRINI, C. D. Análise microgenética da} oficina criativa: projeto de modelagem em argila. São Paulo: Casa do Psicólogo, 2004.

ANGERAMI-CAMON, V. A. Psicologia hospitalar: teoria e prática. In:

cap. 1, p.15-28. . (Org.). São Paulo: Pioneira, 2002.

BRASIL, MINISTÉRIO DA SAÚDE. Conselho Nacional da Saúde. Resolução 196/96. Pesquisa com seres humanos. Brasília: Ministério da Saúde, 1996. 26 p. COSTA, R. X. Educação especial por meio da arte. Rev. Integração, Brasília, ano 7, n.19, p. 64-69, 1997. DIAS, R. R. et al. Enfermaria de pediatria: avaliação e intervenção psicológica. In: BAPTISTA, M. N.; DIAS, R. R. (Org.) Psicologia hospitalar: teoria, aplicação e casos clínicos. Rio de Janeiro: Guanabara Koogan, 2003. p. 53-73.

FRANCISQUETTI, A. A. Arte-reabilitação com pacientes vítimas de dano cerebral (AVC). In: CIORNAI $\mathrm{S}$, (org.). Percursos em arteterapia: arteterapia e educação, arteterapia e saúde. São Paulo: Summus; 2005a. v. 64. p. 261-277.

. Arte-reabilitação com portadores de paralisia cerebral (PC). In: CIORNAI S, (org.). Percursos em arteterapia: arteterapia e educação, arteterapia e saúde. São Paulo: Summus; 2005b. v. 64. p. 239-59. . Arte-reabilitação em enfermaria infantil. In:

CIORNAI S, (org.). Percursos em arteterapia: 
VALLADARES, Ana Cláudia Afonso; CARVALHO, Ana Maria Pimenta. PROMoçÃo DE HABILIDADES GRÁFICAS No CONTEXTO DA HOSPITALIZAÇÃO. Revista Eletrônica de Enfermagem, v. 08, n. 01, p. 128 - 133 , $2006 . \quad$ Disponível em http://www.fen.ufg.br/revista/revista8 1/original 16.htm

arteterapia e educação, arteterapia e saúde. São Paulo: Summus; 2005c. v. 64. p. 221-237.

GOLINELLI, R. Arteterapia: um caminho para a expressão dos sentimentos. Arte terapia: Rev. Imagens da transformação, Rio de Janeiro, v. 9, n. 9, p. 199-204, 2002.

LOWENFELD, V.; BRITTAIN, W. L. Desenvolvimento da capacidade criadora. São Paulo: Mestre Jou, 1977. $446 \mathrm{p}$.

MĖREDIEU, F. O desenho infantil. São Paulo: Cultrix, 2000.

PAIN, S.; JARREAU, G. Teoria e prática da arteterapia: a compreensão do sujeito. 2. ed. Porto Alegre: Artes Médicas, 2001.

PHILIPPINI, A. Para entender arteterapia: cartografias da coragem. Rio de Janeiro: WAK, 2005.

SIEGEL, S. Estatística não-paramétrica: para as ciências do comportamento. São Paulo: MgGraw-Hill, 1975.

SIGAUD, C. H. S.; VERÍSSIMO, M. O. R. (Org.) Enfermagem pediátrica: o cuidado de enfermagem à criança e ao adolescente. São Paulo: EPU, 1996.

VALLADARES, A C. A. A arteterapia e a reabilitação psicossocial das pessoas em sofrimento psíquico. In: . (Org.) Arteterapia no novo paradigma de atenção em saúde mental. São Paulo: Vetor, 2004a. p.11-13.

. Arteterapia com crianças hospitalizadas. 2003. 258 f. Dissertação (Mestrado) - Escola de Enfermagem de Ribeirão Preto, Universidade de São Paulo, Ribeirão Preto.

Manejo arteterapêutico no pré-operatório em pediatria. Rev. Eletrônica de Enfermagem (Online).v.6, n.1, p.110-115, 2004b. Disponível em: http://www.fen.ufg.br/revista/revista6 1/pdf/r3 arteterapi a.pdf [Acesso em jan. 2006]

VALLADARES, A. C. A.; CARVALHO, A. M. P. Desenhos que contam histórias ... desvelando o autoretrato de crianças hospitalizadas em arteterapia. Rev. Científica de Arteterapia Cores da Vida (Online). Goiânia: ABCA, v. 1, n. 1, p. 30-45, cap.7, 2005. Disponível em: http://www.brasilcentralarteterapia.cib.net/ [Acesso em mai. 2006].

VALLADARES, A.C.A.; NOVATO, A.C.R.S. Aspectos transformadores da construção em arteterapia com adolescentes. Goiânia: Rev. Eletrônica de Enfermagem (Online). v. 3, n .1, 2001. Disponível em: http://www.fen.ufg.br/revista/revista3 1/arterap.html

(Acesso em mai. 2006].

WHALEY, L. F.; WONG, D. L. Enfermagem pediátrica: elementos essenciais à intervenção efetiva. 5. ed. Rio de Janeiro: Guanabara Koogan, 1999.

ZIMMERMANN, M. F. Arteterapia: uma introdução. In: FICHTNER, N. (Org.). Prevenção, diagnóstico e tratamento dos transtornos mentais da infância e da adolescência: um enfoque desenvolvimental. Porto Alegre: Artes Médicas, 1997.

Artigo original recebido em 07.03 .06

Enviado para publicação em 30/04/2006 